\title{
Applications of a Specialty Bicuspid Aortic Valve Program: Clinical Continuity and Translational Collaboration
}

\author{
Erin E. Crawford ${ }^{1}$, Patrick M. McCarthy ${ }^{1,2, *}$, S. Chris Malaisrie ${ }^{1,2}{ }^{-}$, Jyothy J. Puthumana ${ }^{3,4}$, \\ Joshua D. Robinson 5,6,7, Michael Mark1 6,8, Menghan Liu ${ }^{1}$, Adin-Cristian Andrei ${ }^{9}$, \\ David G. Guzzardi ${ }^{10,11}$, Jane Kruse ${ }^{1}$ and Paul W. M. Fedak 1,10,11,*(D) \\ 1 Division of Cardiac Surgery, Northwestern Medicine, Chicago, IL 60611, USA; ; ecrawfor@nm.org (E.E.C.); \\ chris.malaisrie@nm.org (S.C.M.); menghan.liu@northwestern.edu (M.L.); JKruse@nm.org (J.K.) \\ 2 Department of Surgery, Feinberg School of Medicine, Northwestern University, Chicago, IL 60611, USA \\ 3 Division of Cardiology, Northwestern Medicine, Chicago, IL 60611, USA; jyothy.puthumana@nm.org \\ 4 Department of Internal Medicine, Feinberg School of Medicine, Northwestern University, \\ Chicago, IL 60611, USA \\ 5 Division of Cardiology, Ann \& Robert H Lurie Children's Hospital of Chicago, Chicago, IL 60611, USA; \\ jdrobinson@luriechildrens.org \\ 6 Department of Radiology, Feinberg School of Medicine, Northwestern University, Chicago, IL 60611, USA; \\ mmarkl@northwestern.edu \\ 7 Department of Pediatrics, Feinberg School of Medicine, Northwestern University, Chicago, IL 60611, USA \\ 8 McCormick School of Engineering, Evanston, IL 60208, USA \\ 9 Department of Preventive Medicine, Feinberg School of Medicine, Northwestern University, Chicago, \\ IL 60611, USA; Adin-Cristian.Andrei@nm.org \\ 10 Section of Cardiac Surgery, Department of Cardiac Sciences, Cumming School of Medicine, University of \\ Calgary, Calgary, AB T2N 4N1, Canada; dgguzzardi@gmail.com \\ 11 Libin Cardiovascular Institute, Calgary, AB T2N 4N1, Canada \\ * Correspondence: Patrick.McCarthy@nm.org (P.M.M.); paul.fedak@gmail.com (P.W.M.F.)
}

Received: 10 March 2020; Accepted: 21 April 2020; Published: 5 May 2020

\begin{abstract}
Bicuspid aortic valve (BAV) is a common congenital heart diagnosis and is associated with aortopathy. Current guidelines for aortic resection have been validated but are based on aortic diameter, which is insufficient to predict acute aortic events. Clinical and translational collaboration is necessary to identify biomarkers that can individualize the timing of prophylactic surgery for BAV aortopathy. We describe our multidisciplinary BAV program, including research protocols aimed at biomarker discovery and results from our longitudinal clinical registry. From 2012-2018, 887 patients enrolled in our clinical BAV registry with the option to undergo four dimensional flow cardiovascular magnetic resonance imaging ( $4 \mathrm{D}$ flow $\mathrm{CMR}$ ) and donate serum plasma or tissue samples. Of 887 patients, $388(44 \%)$ had an elective BAV-related procedure after initial presentation, while 499 (56\%) continued with medical management. Of medical patients, $44(9 \%)$ had elective surgery after $2.3 \pm 1.4$ years. Surgery patients' biobank donations include $198(46 \%)$ aorta, $374(86 \%)$ aortic valve, and 314 (73\%) plasma samples. The $4 \mathrm{D}$ flow CMR was completed for $215(50 \%)$ surgery patients and $243(49 \%)$ medical patients. Patients with BAV aortopathy can be safely followed by a multidisciplinary team to detect indications for surgery. Paired tissue and hemodynamic analysis holds opportunity for biomarker development in BAV aortopathy.
\end{abstract}

Keywords: bicuspid aortic valve; aortic aneurysm; congenital heart disease; 4D MRI 


\section{Introduction}

Bicuspid aortic valve (BAV) is a common congenital diagnosis involving both the aortic valve and aorta, and is often categorized with connective tissue disorders such as Marfan and Turner syndromes. In adults, BAV typically presents as progressive valve deterioration through aortic stenosis (AS), insufficiency (AI), or infective endocarditis (IE). These valvular complications are accompanied by aortopathy in up to $42 \%$ of cases, including dilatation of the aortic root, ascending aorta, arch, or coarctation [1]. Additionally, both BAV and associated aortopathy are heritable among first-degree relatives (FDR), warranting echocardiographic screening for all FDR of a BAV proband $[2,3]$.

Though BAV is the most common congenital heart diagnosis, the malignancy of BAV-associated aortopathy is challenging to define. Risk-stratification is further complicated by the heterogeneity of BAV—previous studies show patients' phenotypes and risks differ across age groups, sexes, and clinical settings [4-6]. We developed a specialty BAV program with the goals to enhance clinical continuity for patients and families, and to integrate a longitudinal clinical registry with translational research efforts aimed at developing additional biomarkers for BAV aortopathy. This multidisciplinary approach is similar to the 'Heart Team' clinical model for severe aortic stenosis, complex coronary artery disease, and advanced heart failure management [7-10]. To our knowledge, this is a unique approach to BAV management. We aim to share our experience by describing patients' characteristics, treatment courses, and volume of translational specimens collected to date.

\section{Materials and Methods}

\subsection{BAV Registry}

From 2012-2018, 887 patients with BAV enrolled in our single-center registry after presenting to our referral cardiology or cardiac surgery clinic. Patients were assigned to a surgical or medical group based on clinical recommendations at time of presentation. We abstracted baseline and follow up clinical data from the medical record annually, including family history and imaging variables from echocardiography and cardiac magnetic resonance imaging (CMR). Baseline aortic diameter and valve morphology data were abstracted from clinical CMR reports; if a baseline CMR was not available, echocardiography values were used. Beginning in 2017, patients received annual follow up surveys to capture updates in social and family histories, including new BAV screening results of first-degree relatives.

\subsection{Adolescent Transition Clinic}

Once a month, we hold a multidisciplinary transition clinic for 16-26 year old patients with BAV. A team of adult and pediatric providers gradually transfer the patient to the adult cardiology clinic and coordinate FDR screening as needed. These transitioning patients may enroll in the pediatric arm of the aforementioned observational registry. To compute the aortic diameter Z-score in the adolescent population, aortic measurements were normalized using the Boston echocardiography Z-score methods from 2013 and, more recently, 2017.

\subsection{Statistical Methods}

Continuous variables were summarized using means/standard deviations, for discrete ones we presented counts and percentages. Group comparison were based on one-way ANOVA for continuous variables and the Wilcoxon rank sum test or Fisher's exact test (when $<5$ cell counts) for discrete variables. Overall survival from the time of surgery (for surgical patients) or consent (for medical patients) was estimated using the Kaplan-Meier estimator. A comparison of overall survivorship since surgery among the surgical aortic valve replacement (SAVR), SAVR with aneurysm resection $(\mathrm{SAVR}+\mathrm{AN})$ and transcatheter aortic valve replacement (TAVR) groups was based on the log-rank test. Two-sided $p$-values less than $5 \%$ were considered statistically significant, and there were no multiplicity adjustments. All analyses were performed in SAS v 9.4 (SAS Institute: Cary, NC, USA). 


\subsection{Translational Research Enrollment}

Adult patients had the option to undergo the procedure (4D-CMR) for the assessment of BAV-mediated alterations in aortic hemodynamics (flow patterns, wall shear stress) and donate serum plasma samples; those undergoing surgery could opt to donate aortic valve or aorta tissue samples, which were resected per clinical guidelines.

\section{Results}

\subsection{Clinical Demographics}

Of 887 patients (Table 1), 388 (44\%) had an elective BAV-related procedure after initial presentation, while $499(56 \%)$ continued with medical management. The average follow up period was $2.9 \pm 1.8$ years (range of 7.0 days to 7.0 years). Forty four (9\%) medical patients underwent elective surgery after $2.3 \pm 1.4$ years. Five-year survival was $95.6 \%$ in the surgical group, $99.8 \%$ in the medical group, and $96.7 \%$ in the medical-to-surgical group $(p=0.03)$.

Table 1. Baseline characteristics of patients presenting to bicuspid aortic valve (BAV) clinic, by clinical demographics.

\begin{tabular}{|c|c|c|c|c|c|c|c|c|c|c|}
\hline \multirow{2}{*}{$\begin{array}{c}\text { Variable } \\
\text { Age }\end{array}$} & \multirow{2}{*}{$\begin{array}{c}n \\
887\end{array}$} & \multicolumn{2}{|c|}{$\begin{array}{l}\text { Entire Cohort } \\
\quad(n=887)\end{array}$} & \multicolumn{2}{|c|}{$\begin{array}{l}\text { Medical } \\
(n=455)\end{array}$} & \multicolumn{2}{|c|}{$\begin{array}{l}\text { Surgical } \\
(n=388)\end{array}$} & \multicolumn{2}{|c|}{$\begin{array}{c}\text { Medical to } \\
\text { Surgical }(n=44)\end{array}$} & \multirow{2}{*}{$\begin{array}{r}p \text {-Value } \\
<0.001\end{array}$} \\
\hline & & 52.0 & \pm 14.5 & 46.0 & \pm 13.6 & 58.9 & \pm 12.6 & 54.3 & \pm 11.7 & \\
\hline $\begin{array}{l}\text { Maximum aortic } \\
\text { diameter }(\mathrm{mm})\end{array}$ & 636 & 42.1 & \pm 6.4 & 40.7 & \pm 5.2 & 43.9 & \pm 7.3 & 43.4 & \pm 4.5 & 0.001 \\
\hline Gender (female) & 887 & 233 & $(26 \%)$ & 156 & $(34 \%)$ & 73 & $(19 \%)$ & 4 & $(9 \%)$ & $<0.001$ \\
\hline $\begin{array}{c}\text { Family History } \\
\text { BAV }\end{array}$ & 704 & 94 & $(13 \%)$ & 64 & $(14 \%)$ & 25 & $(11 \%)$ & 5 & $(12 \%)$ & 0.52 \\
\hline $\begin{array}{l}\text { Family History of } \\
\text { Ascending Aortic } \\
\text { Aneurysm }\end{array}$ & 859 & 19 & $(2 \%)$ & 16 & $(4 \%)$ & 3 & $(1 \%)$ & 0 & $(0 \%)$ & 0.015 \\
\hline $\begin{array}{c}\text { Sievers Fusion } \\
\text { Pattern } \\
\text { Type } 0\end{array}$ & 782 & & & & & & & & & 0.001 \\
\hline Aneroposterior & & 27 & $(3 \%)$ & 12 & $(3 \%)$ & 12 & $(3 \%)$ & 3 & $(8 \%)$ & \\
\hline $\begin{array}{l}\text { Lateral } \\
\text { Type } 1\end{array}$ & & 24 & $(3 \%)$ & 8 & $(2 \%)$ & 14 & $(4 \%)$ & 2 & $(5 \%)$ & \\
\hline $\begin{array}{l}\text { Right-Left } \\
\text { Coronary }\end{array}$ & & 574 & $(73 \%)$ & 308 & $(77 \%)$ & 245 & $(71 \%)$ & 21 & $(53 \%)$ & \\
\hline Right-Noncoronary & & 124 & $(16 \%)$ & 61 & $(15 \%)$ & 54 & $(16 \%)$ & 9 & $(23 \%)$ & \\
\hline Left-Noncoronary & & 9 & $(1 \%)$ & 6 & $(2 \%)$ & 2 & $(1 \%)$ & 1 & $(3 \%)$ & \\
\hline $\begin{array}{c}\text { Type } 2 \\
\text { (Unicuspid) }\end{array}$ & & 24 & $(3 \%)$ & 3 & $(1 \%)$ & 17 & $(5 \%)$ & 4 & $(10 \%)$ & \\
\hline
\end{tabular}

The age range of all patients in our adult cohort was 20 to 89 years. None of our medically-followed patients had an aortic dissection during the follow up period. Endocarditis was a surgical indication for $10(2 \%)$ patients in the surgical group and none in the medical to surgical group. Three (1\%) patients in the medical group have a history of chronic endocarditis, managed medically.

A total of 107 (15\%) patients report a family history of BAV. Of these, $94(13 \%)$ patients had a known family history of BAV at baseline and an additional 13 (2\%) discovered one or more family members with BAV through follow up screening. Family screening of 250 FDR (from 130 families) identified 16 new FDR with BAV, 11 of whom subsequently enrolled in our BAV program.

\subsection{Surgical and Transcatheter Interventions}

The total 432 BAV procedures included 224 (52\%) SAVR, 163 (38\%) SAVR + AN, 18 (4\%) aortic valve repairs (9 (50\%) with $\mathrm{AN}), 15(3 \%)$ valve-sparing root repairs; and 12 (3\%) TAVR (Table 2). Bioprosthetic valves were used in 364 (91\%) SAVR and SAVR + AN. Hemiarch was performed for 
$70(16 \%)$ surgeries. Thirty-day survival for all procedures was $99 \%$, with no significant differences in overall survival in follow up ( $p=0.30$, Figure 1).

One patient had a previous balloon aortic valvuloplasty, six (1.3\%) had a history of aortic coarctation (none with previous repair), and nine $(2 \%)$ had a previous congenital surgery or procedure.

Table 2. Characteristics of surgery group by procedure.

\begin{tabular}{|c|c|c|c|c|c|c|c|c|c|c|}
\hline \multirow{2}{*}{$\begin{array}{c}\text { Variable } \\
\text { Age }\end{array}$} & \multirow{2}{*}{$\begin{array}{c}n \\
399\end{array}$} & \multicolumn{2}{|c|}{$\begin{array}{l}\text { Entire Cohort } \\
\quad(n=399)\end{array}$} & \multicolumn{2}{|c|}{$\begin{array}{l}\text { SAVR only } \\
(n=224)\end{array}$} & \multicolumn{2}{|c|}{$\begin{array}{c}\text { SAVR + AN } \\
(n=163)\end{array}$} & \multicolumn{2}{|c|}{ TAVR $(n=12)$} & \multirow{2}{*}{$\begin{array}{l}p \text {-Value } \\
<0.001\end{array}$} \\
\hline & & 59.5 & \pm 12.0 & 60.9 & \pm 11.6 & 56.4 & \pm 11.2 & 76.2 & \pm 9.7 & \\
\hline Maximum & & & & & & & & & & \\
\hline $\begin{array}{l}\text { Aortic } \\
\text { Diameter } \\
(\mathrm{mm})\end{array}$ & $\begin{array}{c}388 \\
(213,163,12)\end{array}$ & 42.9 & \pm 6.9 & 38.6 & \pm 4.5 & 48.9 & \pm 4.7 & 38.3 & \pm 4.7 & $<0.001$ \\
\hline $\begin{array}{l}\text { Gender } \\
\text { (female) }\end{array}$ & 399 & 95 & $(23.8 \%)$ & 64 & $(28.6 \%)$ & 27 & $(16.6 \%)$ & 4 & $(33.3 \%)$ & 0.017 \\
\hline Pure AI & 399 & 46 & $(11.5 \%)$ & 15 & $(6.7 \%)$ & 31 & $(19.0 \%)$ & 0 & $(0.0 \%)$ & $<0.001$ \\
\hline $\begin{array}{l}\text { Bioprosthetic } \\
\text { valve }\end{array}$ & 399 & 364 & $(91.2 \%)$ & 215 & $(96.0 \%)$ & 149 & $(91.4 \%)$ & 0 & $(0.0 \%)$ & $<0.001$ \\
\hline $\begin{array}{l}\text { 30-Day } \\
\text { Mortality }\end{array}$ & 399 & 3 & $(0.8 \%)$ & 1 & $(0.4 \%)$ & 2 & $(1.2 \%)$ & 0 & $(0.0 \%)$ & 0.649 \\
\hline $\begin{array}{l}\text { Free from } \\
\text { Aortic Valve } \\
\text { Reoperation }\end{array}$ & $\begin{array}{c}290 \\
(172,112,6)\end{array}$ & 284 & $(97.9 \%)$ & 167 & $(97.1 \%)$ & 111 & $(99.1 \%)$ & 6 & $(100 \%)$ & 0.475 \\
\hline $\begin{array}{c}\text { Free from Late } \\
\text { Aortic }\end{array}$ & 290 & & & & & & & & & \\
\hline $\begin{array}{l}\text { Valve-in-valve } \\
\text { Procedure }\end{array}$ & $(172,112,6)$ & 289 & (99.7\%) & 171 & $(99.4 \%)$ & 112 & $(100 \%)$ & 6 & $(100 \%)$ & 0.709 \\
\hline $\begin{array}{c}\text { Free from Late } \\
\text { Aortic } \\
\text { Intervention }\end{array}$ & $\begin{array}{c}290 \\
(172,112,6)\end{array}$ & 289 & $(99.7 \%)$ & 172 & $(100 \%)$ & 111 & $(99.1 \%)$ & 6 & $(100 \%)$ & 0.451 \\
\hline
\end{tabular}

Excludes patients with valve sparing root replacement $(n=15)$ and aortic valve repair $(n=18)$.

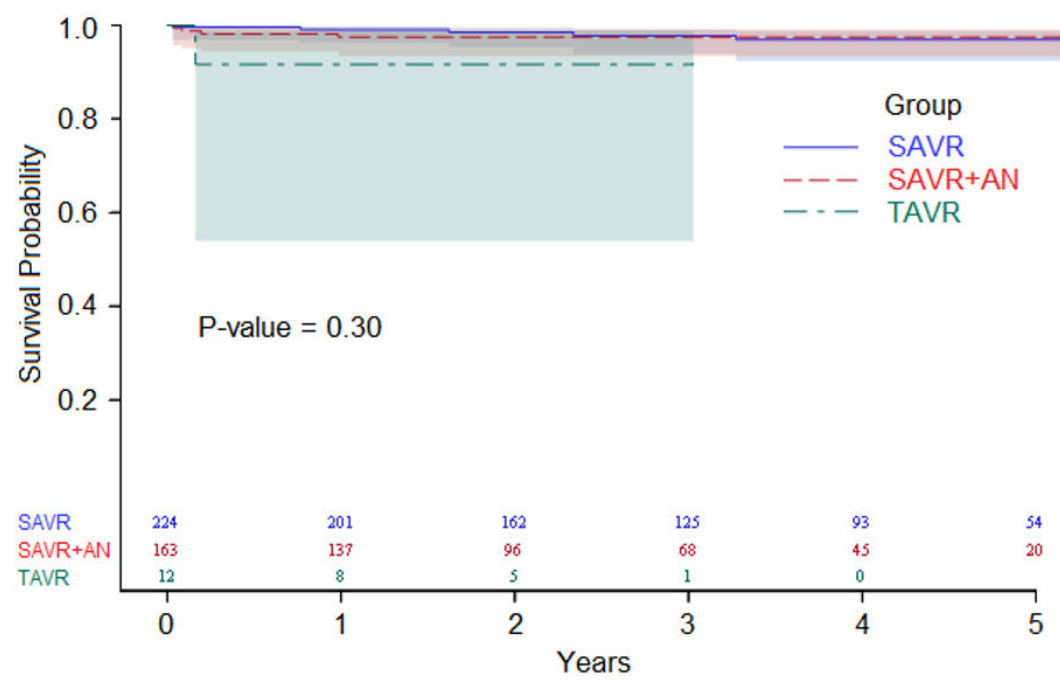

Figure 1. Overall survival estimates in the surgical or transcatheter interventions group.

\subsection{Adolescent Transition Clinic}

Since 2016, 45 (54\%) of 83 adolescent patients from our transition clinic enrolled in our registry, $17(38 \%)$ demonstrate moderate or more AS, moderate or more AI, or an ascending aortic diameter with Z-score greater than 4 by echocardiogram (Table 3$)$. Three $(7 \%)$ patients have a history of aortic coarctation, two of which are now post-repair. One patient underwent successful aortic valve and ascending aorta replacement at our pediatric center; preoperatively, he had symptomatic moderate-severe aortic stenosis (peak velocity $4.0 \mathrm{~m} / \mathrm{s}$ ) and severe aortic regurgitation (regurgitant 
fraction $31-37 \%$ with left ventricular volume indexed to $\left.130 \mathrm{~mL} / \mathrm{m}^{2}\right)$. His ascending aorta measured $45 \mathrm{~mm}$ with a Z-score of +5.76 .

Sixteen FDR (from eight families) were referred to our adult center for family screening, leading to detection of BAV in one (6\%) family member, who established care in our adult BAV clinic. In surveying patient encounters across all ages, four pediatric patients have transitioned to the adult cardiology clinic since their initial visit in the transition clinic.

Table 3. Baseline Characteristics of Patients Presenting to BAV Bridge Transition Clinic.

\begin{tabular}{|c|c|c|c|}
\hline \multirow{2}{*}{ Variable } & \multirow{2}{*}{$n$} & \multicolumn{2}{|c|}{ Entire Cohort } \\
\hline & & \multicolumn{2}{|c|}{$(n=45)$} \\
\hline Age (years) & 45 & 19.6 & \pm 2.8 \\
\hline Max aortic diameter (mm) & 39 & 31.8 & \pm 6.6 \\
\hline Aortic diameter $Z$ score $>4$ & 38 & 7 & $18.4 \%$ \\
\hline Gender, Male & 45 & 36 & $80.0 \%$ \\
\hline Family history of BAV & 40 & 9 & $22.5 \%$ \\
\hline Family history of thoracic aneurysm & 40 & 3 & $7.5 \%$ \\
\hline History of aortic coarctation & 44 & 3 & $6.8 \%$ \\
\hline History of infective endocarditis & 44 & 0 & $0.0 \%$ \\
\hline History of aortic valve procedure & 44 & 2 & $4.5 \%$ \\
\hline History of congenital surgery/procedure & 44 & 2 & $4.5 \%$ \\
\hline Aortic Stenosis & 41 & & \\
\hline Mild & & 8 & $19.5 \%$ \\
\hline Yes & & 4 & $9.8 \%$ \\
\hline Aortic Insufficiency & 41 & & \\
\hline Trivial & & 8 & $19.5 \%$ \\
\hline Mild & & 13 & $31.7 \%$ \\
\hline Moderate & & 5 & $12.2 \%$ \\
\hline Severe & & 1 & $2.4 \%$ \\
\hline None & & 14 & $35.0 \%$ \\
\hline Fusion Pattern & 42 & & \\
\hline LAT- No Raphe & & 1 & $2.4 \%$ \\
\hline Right-Left (R-L) & & 18 & $42.9 \%$ \\
\hline Right-Noncoronary (R-N) & & 3 & $7.1 \%$ \\
\hline RL-RN & & 1 & $2.4 \%$ \\
\hline Undetermined & & 19 & $45.2 \%$ \\
\hline
\end{tabular}

\subsection{Translational Research Enrollment}

Of all surgery patients, 198 (46\%) donated aortic tissue samples, 374 (86\%) donated aortic valve samples, and 314 (73\%) donated plasma samples (vs. 84\% of the medical group). The $4 \mathrm{D}$ flow CMR (Figure 2) was completed for $215(50 \%)$ surgery patients and $243(49 \%)$ of all medical patients. 
A: 2D CINE MRI
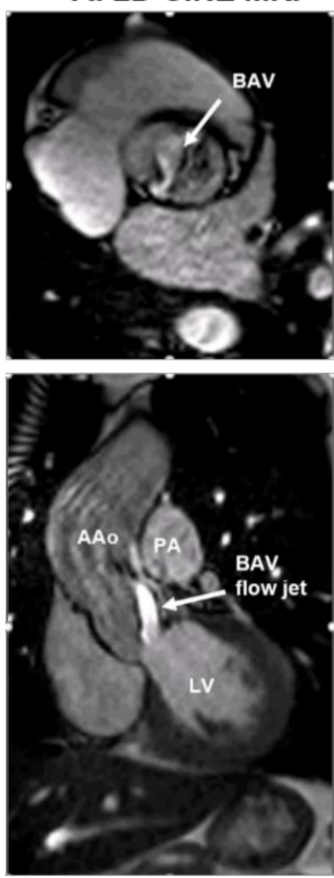

B: 4D Flow MRI

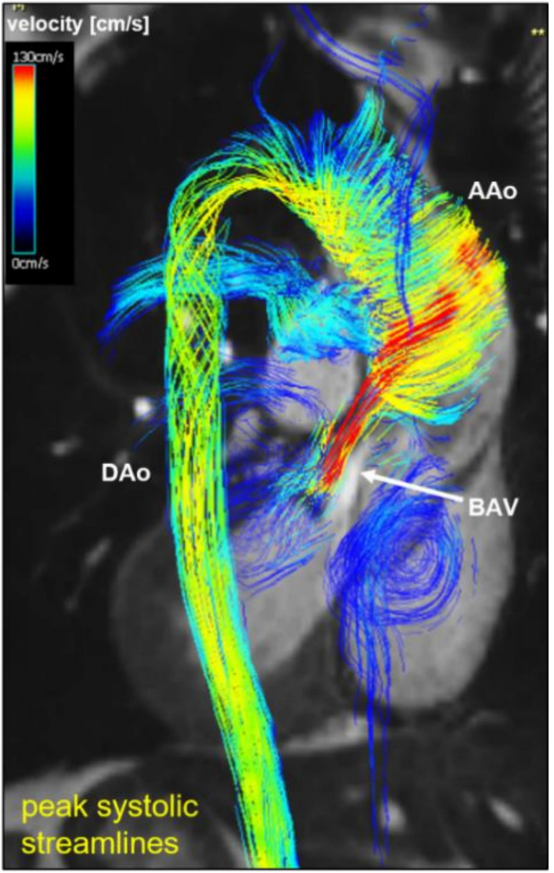

Figure 2. The 2D CINE (A) and $4 \mathrm{D}$ flow cardiovascular magnetic resonance (CMR) (B) in a 32-year old patient with bicuspid aortic valve (BAV, right-noncoronary (R-N) valve fusion pattern), aortic dilatation (Sinus of Valsalva/Mid Ascending Aorta diameter $=42 / 45 \mathrm{~mm}$ ), moderate aortic valve stenosis (aortic valve area $=1.5 \mathrm{~cm}^{2}$ ). A: 2D CINE MRI during peak systole shows limited BAV opening (top) and the associated outflow jet (bottom) B: 3D streamline visualization of systolic blood flow in the thoracic aortic as assessed by 4D flow CMR and shows a marked high-velocity (red color) valve outflow jet directed toward the anterior wall of the ascending aorta (AAo). Note the formation of a complex helix flow pattern in the entire AAo. In addition, 4D flow CMR provides full volumetric coverage of the thoracic aorta and flexible retrospective quantification of peak systolic velocities at multiple locations in the thoracic aorta. $\mathrm{LV}=$ left ventricle, $\mathrm{PA}=$ pulmonary artery, DAo = descending aorta.

\section{Discussion}

\subsection{Specialty BAV Program in the Era of the Heart Team}

Multidisciplinary collaboration between cardiologists, cardiac surgeons, nurse coordinators, and imaging specialists is an increasingly common approach to managing cardiac diagnoses. The 'Heart Team' was coined to represent variations of this shared decision-making model for treatment of severe aortic stenosis, complex coronary artery disease, and advanced heart failure [8-11]. Our BAV program functions similarly to the Heart Team, but with additional emphasis on translational research and intergenerational screening. Other centers treating BAV aortopathy may find all or parts of our framework helpful, or better yet, expand on it with their own strengths or areas of expertise.

\subsection{Clinical Demographics}

Data from large groups of patients with BAV suggest excellent long-term outcomes with very low risk of catastrophic events and survival similar to a non-BAV cohort. Most patients are referred to our BAV program based on clinical findings suggestive of significant AS or AI, or an incidental finding of aortopathy noted on imaging. The incidence of BAV endocarditis is $2 \%$ in contemporary BAV cohorts, which is similar to our experience and 16 times higher than the incidence of the general population [12]. Both transthoracic echocardiography (TTE) and transesophageal echocardiography (TEE) are critical in diagnosis and clinical decision-making for infective endocarditis $[13,14]$. 
We note that our series describes patients presenting to a referral center, with clinical courses and phenotypes that differ from those followed in the community setting [4-6]. While patients with valvular manifestations will eventually develop symptoms as the disease progresses, those with aortopathy as a sole manifestation may have a clinically silent course, underscoring the importance of serial aortic imaging strategy.

\subsection{Imaging of the Aorta}

Due to the asymmetric nature of aortopathy in BAV, recent BAV aortopathy guidelines recommend ECG-gated CT or MR angiography (CTA or MRA) as the gold standard imaging modality, due to their use of the double-oblique technique to measure aortic diameter perpendicular to the longitudinal axis of the aorta [15]. Additionally, CTA and MRA permit repeat measurements at precise locations along the aorta for consistent comparison between serial studies. If MRA or CTA are contraindicated for a patient, the aorta may be measured by TTE from leading edge-to-leading edge at end-diastole, which correlates best with CTA and MRA diastolic inner wall to inner wall measurement $[15,16]$.

MRA is an attractive option for aortic imaging for BAV aortopathy as it minimizes contrast and radiation exposure for patients who tend to present at a young age and may require multiple studies before meeting a surgical endpoint $[17,18]$. Additionally, information about wall shear stress from 4D flow CMR analysis has the potential to reach diagnostic quality without the use of contrast [19].

If baseline root and tubular ascending diameters are normal, follow up monitoring can be performed every 3-5 years. This practice aligns with the guideline recommendations for annual imaging if the baseline root and/or tubular ascending diameters are dilated (40-49 $\mathrm{mm})$, reducing frequency to every 2 years if no progression is noted between serial studies [15]. If root and/or tubular ascending diameters are 50-54 mm, annual or semiannual imaging are warranted. Aortopathy progression tends to be faster in patients with BAV versus those with trileaflet aortic valve (TAV): some studies report an average aortic growth rate of $1.9 \mathrm{~mm} /$ year in BAV versus $1.3 \mathrm{~mm} /$ year in patients with TAV [17] another study suggests an even slower growth rate of 0.4-0.6 mm/year [20].

The abdominal and pelvic aorta do not require monitoring in isolated BAV disease, unless a family history of abdominal or iliac aneurysms is present [21]. Although intracranial arterial aneurysms have been found more commonly in patients with BAV, there is no increased prevalence of intracranial aneurysm-related subarachnoid hemorrhages in BAV patients other than patients with coarctation; therefore, routine brain angiography is only recommended in patients with BAV and concomitant coarctation of the aorta $[15,22,23]$.

\subsection{Family Screening}

Previous family screening studies report finding BAV in FDR of $9-11 \%$ of BAV index patients [2,24-26]. These were cross-sectional, single-center studies with consistent screening protocols and inter-reader validity. Our longitudinal series reports a slightly higher rate of BAV family history (15\%), possibly because patients are surveyed annually for updates in family screening. This allows us to capture screening results from outside centers, overcoming logistical and geographical barriers to screening complete sets of FDR.

In addition to BAV heredity, FDR are more likely to have a dilated aorta, with or without concomitant BAV [2]. Nineteen (2\%) patients in our program reported a family history of thoracic aortic aneurysm, two of which required aortic resection during the follow up period. Additionally, one patient reported a new family history of aortic dissection in an otherwise healthy family member with a TAV aneurysm.

Recent studies propose familial inheritance of a milder phenotype of BAV, marked by a smaller cusp fusion, the presence of aortic dilation, and atypical aortic blood flow and wall shear stress $[25,27,28]$. The smaller raphe in these family members is often missed by echocardiography—the standard imaging modality used for FDR screening-suggesting that familial clustering of BAV is underestimated. 


\subsection{Surgical and Transcatheter Interventions}

The majority of patients facing surgery for BAV valvulopathy require valve replacement for aortic stenosis. Recently, TAVR has become an alternative to SAVR for BAV patients with AS. Outcomes for TAVR in highly selected BAV patients with AS have improved significantly with newer generation valves and is well accepted in patients with a high and intermediate surgical risk [29]. However, the higher rate of stroke, annular rupture, and need for permanent pacemakers remain concerns when considering TAVR for the more typical young BAV patient with low-surgical risk [30,31]. Randomized clinical trials for BAV patients with AS have not been performed, and until both safety and long-term efficacy are demonstrated, SAVR with or without aneurysm repair should be considered the gold standard therapy for these patients.

Guidelines recommend bioprosthetic valve replacement for patients 60 years and older, with the expectation that valve durability lasts 15-20 years in this age group [32]. Bioprosthetic valves are also an attractive option for patients who want to avoid managing Coumadin protocols for stroke prophylaxis after mechanical aortic valve replacement. Should the bioprosthetic valve degenerate later in life, it can be replaced through a transcatheter valve-in-valve procedure; this bypasses the need for a repeat sternotomy in an older and likely higher-risk patient [33]. These considerations and patient preference factor into our use of bioprosthetic valves in 91\% of the SAVR cohort (Table 2: median age $58 \pm 12$ years). Our follow up period is short, however a contemporary study of patients aged 50-69 years suggests patients with mechanical or bioprosthetic aortic valve replacements show no significant difference in survival at 15 years [34].

Current guidelines recommend prophylactic aortic resection for diameters between $45 \mathrm{~mm}$ and $55 \mathrm{~mm}$, depending on indications for concomitant valve intervention and risk factors for surgery [15]. For patients without valve disease, aortic resection may be postponed until the aorta reaches $55 \mathrm{~mm}$. Risk factors such as family history of thoracic aortic dissection or aortic growth rate $>5.0$ mm per year merit aortic resection at a smaller diameter threshold. Patients undergoing a valve replacement or repair may undergo concomitant aortic resection if the aorta measures $45 \mathrm{~mm}$ or greater, which is validated as safe [35]. These guidelines for prophylactic aortic replacement are governed by aortic diameter, which is insufficient to predict acute aortic events for BAV aortopathy [15]. The need for biomarkers and advanced imaging to refine surgery timing is well-established [36,37].

\subsection{Adolescent Transition Clinic}

Longitudinal studies of congenital heart disease are limited by the inability to connect pediatric disease progression with adult outcomes. Through the creation of a dedicated, adolescent transition clinic, we have established a single clinical registry for pediatric and adult patients with a unified data dictionary. A dedicated social worker is also embedded in the clinic to help assess and promote transition readiness and to help families navigate insurance changes across young adulthood. Though not every pediatric patient is ultimately funneled through the transition clinic, many of the most severe cases or advanced phenotypes are concentrated in this multidisciplinary clinic. Compared to another large institutional cohort of pediatric patients with isolated BAV in which 7\% of subjects had moderate aortic regurgitation or greater and the median ascending aorta Z score was +2.3 [38], our transition clinic represents an enriched population with nearly $40 \%$ of patients having important valve disease or aortopathy. Given that loss to follow up in the adult congenital heart disease population is associated with male sex, moderate disease complexity, fewer pediatric interventions, a gap in insurance coverage or lack of a transition program $[39,40]$, and that lapses in care increase the risk of urgent cardiac intervention [41], the adolescent BAV transition clinic addresses an important gap for an "at risk" population. Similarly, this collaboration has facilitated screening of FDR across all age ranges, including fetal counseling. 


\subsection{Translational Research Participation}

Aortic diameter and growth rate are only surrogates for the risk of acute aortic syndromes, yet they underlie contemporary surgical decision-making in BAV aortopathy [36,42]. Moreover, considerable variability in surgical management can be attributed to differing perceptions of the role BAV-mediated hemodynamics play in the expression of ascending aortopathy [43].

To address this unmet need for noninvasive biomarkers that more closely reflect aortic wall integrity on a patient-by-patient basis, we used 4D flow CMR (Figure 2) in BAV patients prior to surgery to quantify wall shear stress (WSS) - a hemodynamic parameter known to influence aortic wall remodeling in animal models [44-46]. Patient tissue that was collected intraoperatively was compared within each patient's aorta for histopathology, molecular markers of aortopathy and biomechanical testing. This unique methodology enabled patients to serve as their own internal controls. We documented that, compared to regions subjected to normal WSS, adjacent regions in each aorta subjected to elevated WSS exhibited greater quantitative histopathology and molecular markers of aortopathy, as well as differences in biomechanical testing [19]. Furthermore, we found that the magnitude of elevated WSS directly correlated with aortopathy expression in the tissue, in addition to differences in valve phenotype (AS vs. AI) and ascending aortic diameter [47].

This work shows that noninvasive hemodynamic biomarkers can be mapped in the aortas of human patients and corresponds to the location and severity of disease. With further validation, mapping diseased tissue using this technology could allow surgeons to strategize what tissue should be removed, as well as what tissue is healthy and should be left in individual patients; they can be as aggressive or conservative as needed for individualized patient treatment.

\section{Conclusions}

The clinical and translational research needs of the BAV patient population warrant a clinical model which supports the patient-family with BAV and promotes translational efforts that may refine surgical timing for subsequent generations. Dedicated clinical support for BAV family screening can help detect first-degree relatives with BAV or aortopathy. Patients can be safely followed by a multidisciplinary team to detect indications for surgery and provide comprehensive care to the entire family with BAV.

Author Contributions: Conceptualization (P.M.M., P.W.M.F.); Data Curation (E.E.C., M.L., J.K.); Formal Analysis (M.L., A.-C.A.); Project Administration (E.E.C.); Writing—Original Draft Preparation (E.E.C., S.C.M., J.J.P., M.M., J.D.R., D.G.G.); Writing - Review and Editing (E.E.C., P.M.M., P.W.M.F.). All authors have read and agreed to the published version of the manuscript.

Funding: This research received no external funding.

Acknowledgments: Development of Northwestern Medicine's Bicuspid Aortic Valve Program was made possible by the support of the Martha and Richard Melman family.

Conflicts of Interest: The authors declare no conflict of interest.

\section{References}

1. Masri, A.; Kalahasti, V.; Alkharabsheh, S.; Svensson, L.G.; Sabik, J.F.; Roselli, E.E.; Hammer, D.; Johnston, D.R.; Collier, P.; Rodriguez, L.L.; et al. Characteristics and long-term outcomes of contemporary patients with bicuspid aortic valves. J. Thorac. Cardiovasc. Surg. 2016, 151, 1650-1659. [CrossRef]

2. Dayan, V.; Zuasnabar, A.; Citro, R.; Bossone, E.; Michelena, H.I.; Parma, G.; Bellino, M.; Olascoaga, A.; Florio, L.; Body, S.; et al. Aortopathy and regurgitation in bicuspid valve patients increase the risk of aortopathy in relatives. Int. J. Cardiol. 2019, 286, 117-120. [CrossRef]

3. Biner, S.; Rafique, A.M.; Ray, I.; Cuk, O.; Siegel, R.J.; Tolstrup, K. Aortopathy is prevalent in relatives of bicuspid aortic valve patients. J. Am. Coll. Cardiol. 2009, 53, 2288-2295. [CrossRef] 
4. Andrei, A.C.; Yadlapati, A.; Malaisrie, S.C.; Puthumana, J.J.; Li, Z.; Rigolin, V.H.; Mendelson, M.; Clennon, C.; Kruse, J.; Fedak, P.W.; et al. Comparison of outcomes and presentation in men-versus-women with bicuspid aortic valves undergoing aortic valve replacement. Am. J. Cardiol. 2015, 116, 250-255. [CrossRef]

5. Michelena, H.I.; Suri, R.M.; Katan, O.; Eleid, M.F.; Clavel, M.A.; Maurer, M.J.; Pellikka, P.A.; Mahoney, D.; Enriquez-Sarano, M. Sex Differences and Survival in Adults With Bicuspid Aortic Valves: Verification in 3 Contemporary Echocardiographic Cohorts. J. Am. Heart Assoc. 2016, 5, e004211. [CrossRef] [PubMed]

6. Rodrigues, I.; Agapito, A.F.; De Sousa, L.; Oliveira, J.A.; Branco, L.M.; Galrinho, A.; Abreu, J.; Timoteo, A.T.; Rosa, S.A.; Ferreira, R.C. Bicuspid aortic valve outcomes. Cardiol. Young 2017, 27, 518-529. [CrossRef] [PubMed]

7. Holmes, D.R., Jr.; Rich, J.B.; Zoghbi, W.A.; Mack, M.J. The heart team of cardiovascular care. J. Am. Coll. Cardiol. 2013, 61, 903-907. [CrossRef] [PubMed]

8. Holmes, D.R., Jr.; Mohr, F.; Hamm, C.W.; Mack, M.J. Venn diagrams in cardiovascular disease: The Heart Team concept. Ann. Thorac. Surg. 2013, 95, 389-391. [CrossRef]

9. Coylewright, M.; Mack, M.J.; Holmes, D.R., Jr.; O'Gara, P.T. A call for an evidence-based approach to the Heart Team for patients with severe aortic stenosis. J. Am. Coll. Cardiol. 2015, 65, 1472-1480. [CrossRef]

10. Head, S.J.; Kaul, S.; Mack, M.J.; Serruys, P.W.; Taggart, D.P.; Holmes, D.R., Jr.; Leon, M.B.; Marco, J.; Bogers, A.J.; Kappetein, A.P. The rationale for Heart Team decision-making for patients with stable, complex coronary artery disease. Eur. Heart J. 2013, 34, 2510-2518. [CrossRef]

11. Bonow, R.O.; Brown, A.S.; Gillam, L.D.; Kapadia, S.R.; Kavinsky, C.J.; Lindman, B.R.; Mack, M.J.; Thourani, V.H. ACC/AATS/AHA/ASE/EACTS/HVS/SCA/SCAI/SCCT/SCMR/STS 2017 Appropriate Use Criteria for the Treatment of Patients With Severe Aortic Stenosis: A Report of the American College of Cardiology Appropriate Use Criteria Task Force, American Association for Thoracic Surgery, American Heart Association, American Society of Echocardiography, European Association for Cardio-Thoracic Surgery, Heart Valve Society, Society of Cardiovascular Anesthesiologists, Society for Cardiovascular Angiography and Interventions, Society of Cardiovascular Computed Tomography, Society for Cardiovascular Magnetic Resonance, and Society of Thoracic Surgeons. J. Am. Coll. Cardiol. 2017, 70, 2566-2598. [PubMed]

12. Michelena, H.I.; Katan, O.; Suri, R.M.; Baddour, L.M.; Enriquez-Sarano, M. Incidence of Infective Endocarditis in Patients With Bicuspid Aortic Valves in the Community. Mayo Clin. Proc. 2016, 91, 122-123. [CrossRef] [PubMed]

13. Afonso, L.; Kottam, A.; Reddy, V.; Penumetcha, A. Echocardiography in Infective Endocarditis: State of the Art. Curr. Cardiol. Rep. 2017, 19, 127. [CrossRef] [PubMed]

14. Bai, A.D.; Steinberg, M.; Showler, A.; Burry, L.; Bhatia, R.S.; Tomlinson, G.A.; Bell, C.M.; Morris, A.M. Diagnostic Accuracy of Transthoracic Echocardiography for Infective Endocarditis Findings Using Transesophageal Echocardiography as the Reference Standard: A Meta-Analysis. J. Am. Soc. Echocardiogr. 2017, 30, 639-646. [CrossRef] [PubMed]

15. Borger, M.A.; Fedak, P.W.M.; Stephens, E.H.; Gleason, T.G.; Girdauskas, E.; Ikonomidis, J.S.; Khoynezhad, A.; Siu, S.C.; Verma, S.; Hope, M.D.; et al. The American Association for Thoracic Surgery consensus guidelines on bicuspid aortic valve-related aortopathy: Full online-only version. J. Thorac. Cardiovasc. Surg. 2018, 156, e41-e74. [CrossRef] [PubMed]

16. Goldstein, S.A.; Evangelista, A.; Abbara, S.; Arai, A.; Asch, F.M.; Badano, L.P.; Bolen, M.A.; Connolly, H.M.; Cuellar-Calabria, H.; Czerny, M.; et al. Multimodality imaging of diseases of the thoracic aorta in adults: From the American Society of Echocardiography and the European Association of Cardiovascular Imaging: Endorsed by the Society of Cardiovascular Computed Tomography and Society for Cardiovascular Magnetic Resonance. J. Am. Soc. Echocardiogr. 2015, 28, 119-182.

17. Davies, R.R.; Kaple, R.K.; Mandapati, D.; Gallo, A.; Botta, D.M., Jr.; Elefteriades, J.A.; Coady, M.A. Natural history of ascending aortic aneurysms in the setting of an unreplaced bicuspid aortic valve. Ann. Thorac. Surg. 2007, 83, 1338-1344. [CrossRef]

18. Nishimura, R.A.; Otto, C.M.; Bonow, R.O.; Carabello, B.A.; Erwin, J.P., III; Guyton, R.A.; O'Gara, P.T.; Ruiz, C.E.; Skubas, N.J.; Sorajja, P.; et al. 2014 AHA/ACC guideline for the management of patients with valvular heart disease: Executive summary: A report of the American College of Cardiology/American Heart Association Task Force on Practice Guidelines. J. Am. Coll. Cardiol. 2014, 63, 2438-2488. [CrossRef] 
19. Guzzardi, D.G.; Barker, A.J.; Van Ooij, P.; Malaisrie, S.C.; Puthumana, J.J.; Belke, D.D.; Mewhort, H.E.; Svystonyuk, D.A.; Kang, S.; Verma, S.; et al. Valve-Related Hemodynamics Mediate Human Bicuspid Aortopathy: Insights From Wall Shear Stress Mapping. J. Am. Coll. Cardiol. 2015, 66, 892-900. [CrossRef]

20. Della Corte, A.; Bancone, C.; Buonocore, M.; Dialetto, G.; Covino, F.E.; Manduca, S.; Scognamiglio, G.; D'Oria, V.; De Feo, M. Pattern of ascending aortic dimensions predicts the growth rate of the aorta in patients with bicuspid aortic valve. JACC Cardiovasc. Imaging 2013, 6, 1301-1310. [CrossRef]

21. Warnes, C.A.; Williams, R.G.; Bashore, T.M.; Child, J.S.; Connolly, H.M.; Dearani, J.A.; Del Nido, P.; Fasules, J.W.; Graham, T.P., Jr.; Hijazi, Z.M.; et al. ACC/AHA 2008 guidelines for the management of adults with congenital heart disease: A report of the American College of Cardiology/American Heart Association Task Force on Practice Guidelines (Writing Committee to Develop Guidelines on the Management of Adults With Congenital Heart Disease). Developed in Collaboration With the American Society of Echocardiography, Heart Rhythm Society, International Society for Adult Congenital Heart Disease, Society for Cardiovascular Angiography and Interventions, and Society of Thoracic Surgeons. J. Am. Coll. Cardiol. 2008, 52, e143-e263. [PubMed]

22. Egbe, A.C.; Padang, R.; Brown, R.D.; Khan, A.R.; Luis, S.A.; Huston, J., III; Akintoye, E.; Connolly, H.M. Prevalence and predictors of intracranial aneurysms in patients with bicuspid aortic valve. Heart 2017, 103, 1508-1514. [CrossRef] [PubMed]

23. Schievink, W.I.; Raissi, S.S.; Maya, M.M.; Velebir, A. Screening for intracranial aneurysms in patients with bicuspid aortic valve. Neurology 2010, 74, 1430-1433. [CrossRef] [PubMed]

24. Huntington, K.; Hunter, A.G.; Chan, K.L. A prospective study to assess the frequency of familial clustering of congenital bicuspid aortic valve. J. Am. Coll. Cardiol. 1997, 30, 1809-1812. [CrossRef]

25. Galian-Gay, L.; Carro Hevia, A.; Teixido-Tura, G.; Rodriguez Palomares, J.; Gutierrez-Moreno, L.; Maldonado, G.; Gonzalez-Alujas, M.T.; Sao-Aviles, A.; Gallego, P.; Calvo-Iglesias, F.; et al. Familial clustering of bicuspid aortic valve and its relationship with aortic dilation in first-degree relatives. Heart 2019, 105, 603-608. [CrossRef]

26. Loscalzo, M.L.; Goh, D.L.; Loeys, B.; Kent, K.C.; Spevak, P.J.; Dietz, H.C. Familial thoracic aortic dilation and bicommissural aortic valve: A prospective analysis of natural history and inheritance. Am. J. Med. Genet. A 2007, 143, 1960-1967. [CrossRef]

27. Sperling, J.S.; Lubat, E. Forme fruste or 'Incomplete' bicuspid aortic valves with very small raphes: The prevalence of bicuspid valve and its significance may be underestimated. Int. J. Cardiol. 2015, 184, 1-5. [CrossRef]

28. Guala, A.; Rodriguez-Palomares, J.; Galian-Gay, L.; Teixido-Tura, G.; Johnson, K.M.; Wieben, O.; Sao Aviles, A.; Evangelista, A. Partial Aortic Valve Leaflet Fusion Is Related to Deleterious Alteration of Proximal Aorta Hemodynamics. Circulation 2019, 139, 2707-2709. [CrossRef]

29. Yoon, S.H.; Bleiziffer, S.; De Backer, O.; Delgado, V.; Arai, T.; Ziegelmueller, J.; Barbanti, M.; Sharma, R.; Perlman, G.Y.; Khalique, O.K.; et al. Outcomes in Transcatheter Aortic Valve Replacement for Bicuspid Versus Tricuspid Aortic Valve Stenosis. J. Am. Coll. Cardiol. 2017, 69, 2579-2589. [CrossRef]

30. Mack, M.J.; Leon, M.B.; Thourani, V.H.; Makkar, R.; Kodali, S.K.; Russo, M.; Kapadia, S.R.; Malaisrie, S.C.; Cohen, D.J.; Pibarot, P.; et al. Transcatheter Aortic-Valve Replacement with a Balloon-Expandable Valve in Low-Risk Patients. N. Engl. J. Med. 2019, 380, 1695-1705. [CrossRef]

31. Popma, J.J.; Deeb, G.M.; Yakubov, S.J.; Mumtaz, M.; Gada, H.; O’Hair, D.; Bajwa, T.; Heiser, J.C.; Merhi, W.; Kleiman, N.S.; et al. Transcatheter Aortic-Valve Replacement with a Self-Expanding Valve in Low-Risk Patients. N. Engl. J. Med. 2019, 80, 1706-1715. [CrossRef] [PubMed]

32. Stassano, P.; Di Tommaso, L.; Monaco, M.; Iorio, F.; Pepino, P.; Spampinato, N.; Vosa, C. Aortic valve replacement: A prospective randomized evaluation of mechanical versus biological valves in patients ages 55 to 70 years. J. Am. Coll. Cardiol. 2009, 54, 1862-1868. [CrossRef] [PubMed]

33. Eggebrecht, H.; Schafer, U.; Treede, H.; Boekstegers, P.; Babin-Ebell, J.; Ferrari, M.; Mollmann, H.; Baumgartner, H.; Carrel, T.; Kahlert, P.; et al. Valve-in-valve transcatheter aortic valve implantation for degenerated bioprosthetic heart valves. JACC Cardiovasc. Interv. 2011, 4, 1218-1227. [CrossRef] [PubMed]

34. Chiang, Y.P.; Chikwe, J.; Moskowitz, A.J.; Itagaki, S.; Adams, D.H.; Egorova, N.N. Survival and long-term outcomes following bioprosthetic vs mechanical aortic valve replacement in patients aged 50 to 69 years. JAMA 2014, 312, 1323-1329. [CrossRef] 
35. Rinewalt, D.; McCarthy, P.M.; Malaisrie, S.C.; Fedak, P.W.; Andrei, A.C.; Puthumana, J.J.; Bonow, R.O. Effect of aortic aneurysm replacement on outcomes after bicuspid aortic valve surgery: Validation of contemporary guidelines. J. Thorac. Cardiovasc. Surg. 2014, 148, 2060-2069. [CrossRef]

36. Girdauskas, E.; Petersen, J.; Neumann, N.; Gross, T.; Naito, S.; Hillebrand, M.; Reichenspurner, H.; Blankenberg, S.; Zeller, T. Evaluation of microribonucleic acids as potential biomarkers in the bicuspid aortic valve-associated aortopathy. Interact. Cardiovasc. Thorac. Surg. 2018, 27, 60-66. [CrossRef]

37. Della Corte, A.; Body, S.C.; Booher, A.M.; Schaefers, H.J.; Milewski, R.K.; Michelena, H.I.; Evangelista, A.; Pibarot, P.; Mathieu, P.; Limongelli, G.; et al. Surgical treatment of bicuspid aortic valve disease: Knowledge gaps and research perspectives. J. Thorac. Cardiovasc. Surg. 2014, 147, 1749-1757. [CrossRef]

38. Yamauchi, M.S.W.; Puchalski, M.D.; Weng, H.T.; Pinto, N.M.; Etheridge, S.P.; Presson, A.P.; Tani, L.Y.; Minich, L.L.; Williams, R.V. Disease progression and variation in clinical practice for isolated bicuspid aortic valve in children. Congenit. Heart Dis. 2018, 13, 432-439. [CrossRef]

39. Madsen, C.B.; Hattersley, S.; Buck, J.; Gendel, S.M.; Houben, G.F.; Hourihane, J.O.; Mackie, A.; Mills, E.N.; Norhede, P.; Taylor, S.L.; et al. Approaches to risk assessment in food allergy: Report from a workshop "developing a framework for assessing the risk from allergenic foods". Food Chem. Toxicol. 2009, 47, 480-489. [CrossRef]

40. Gurvitz, M.; Valente, A.M.; Broberg, C.; Cook, S.; Stout, K.; Kay, J.; Ting, J.; Kuehl, K.; Earing, M.; Webb, G.; et al. Prevalence and predictors of gaps in care among adult congenital heart disease patients: HEART-ACHD (The Health, Education, and Access Research Trial). J. Am. Coll. Cardiol. 2013, 61, 2180-2184. [CrossRef]

41. Yeung, E.; Kay, J.; Roosevelt, G.E.; Brandon, M.; Yetman, A.T. Lapse of care as a predictor for morbidity in adults with congenital heart disease. Int. J. Cardiol. 2008, 125, 62-65. [CrossRef] [PubMed]

42. Nissen, A.P.; Thanh Truong, V.T.; Alhafez, B.A.; Puthumana, J.J.; Estrera, A.L.; Body, S.C.; Prakash, S.K.; Investigators, B.A. Gen TACRI: Surgical repair of bicuspid aortopathy at small diameters: Clinical and institutional factors. J. Thorac. Cardiovasc. Surg. 2019. [CrossRef] [PubMed]

43. Verma, S.; Yanagawa, B.; Kalra, S.; Ruel, M.; Peterson, M.D.; Yamashita, M.H.; Fagan, A.; Currie, M.E.; White, C.W.; Wai Sang, S.L.; et al. Knowledge, attitudes, and practice patterns in surgical management of bicuspid aortopathy: A survey of 100 cardiac surgeons. J. Thorac. Cardiovasc. Surg. 2013, 146, 1033-1040.e4. [CrossRef] [PubMed]

44. Prado, C.M.; Ramos, S.G.; Alves-Filho, J.C.; Elias, J., Jr.; Cunha, F.Q.; Rossi, M.A. Turbulent flow/low wall shear stress and stretch differentially affect aorta remodeling in rats. J. Hypertens. 2006, 24, 503-515. [CrossRef]

45. Liu, J.; Liu, Y.; Bin, B.Y.; Li, M.Y.; Huang, R.Z.; Wu, W.L.; Yuan, Y.; Bin, J.P. Effects of high and low shear stress on vascular remodeling and endothelial vascular cell adhesion molecular-1 expression in mouse abdominal aorta. Nan Fang Yi Ke Da Xue Xue Bao 2011, 31, 1349-1352.

46. Fedak, P.W.; De Sa, M.P.; Verma, S.; Nili, N.; Kazemian, P.; Butany, J.; Strauss, B.H.; Weisel, R.D.; David, T.E. Vascular matrix remodeling in patients with bicuspid aortic valve malformations: Implications for aortic dilatation. J. Thorac. Cardiovasc. Surg. 2003, 126, 797-806. [CrossRef]

47. Bollache, E.; Fedak, P.W.M.; Van Ooij, P.; Rahman, O.; Malaisrie, S.C.; McCarthy, P.M.; Carr, J.C.; Powell, A.; Collins, J.D.; Markl, M.; et al. Perioperative evaluation of regional aortic wall shear stress patterns in patients undergoing aortic valve and/or proximal thoracic aortic replacement. J. Thorac. Cardiovasc. Surg. 2018, 155, 2277-2286. [CrossRef]

(C) 2020 by the authors. Licensee MDPI, Basel, Switzerland. This article is an open access article distributed under the terms and conditions of the Creative Commons Attribution (CC BY) license (http://creativecommons.org/licenses/by/4.0/). 